\title{
Triple Negative Breast Carcinoma: A Comparative Study between Breast Lesion and Lymph Node Metastases: A Preliminary Study
}

\author{
David Parada, ${ }^{1}$ Karla Peña, ${ }^{1}$ Francesc Riu, ${ }^{1}$ and Pilar Hernandez ${ }^{2}$ \\ ${ }^{1}$ Servei de Patologia, Hospital Universitari Sant Joan de Reus, Institut d’Investigació Sanitaria Pere Virgili (IISPV), \\ Universitat Rovira i Virgili, Reus, 43206 Tarragona, Spain \\ ${ }^{2}$ Epidemiología, Estadística i Bioinformàtica, Institut d'Investigació Sanitaria Pere Virgili (IISPV), Universitat Rovira i Virgili, \\ Reus, 43007 Tarragona, Spain \\ Correspondence should be addressed to David Parada,dparada@grupsagessa.com
}

Received 18 May 2011; Accepted 14 June 2011

Academic Editors: A. Gocht, A. Pagani, T. Shien, and A. Stringer

Copyright (๑) 2011 David Parada et al. This is an open access article distributed under the Creative Commons Attribution License, which permits unrestricted use, distribution, and reproduction in any medium, provided the original work is properly cited.

\begin{abstract}
Aims and Background. Triple negative breast carcinoma is a genetic and molecular subtype of breast carcinoma with poor prognosis. Some immunohistochemistry studies have been proposed to identify BLBC. Most studies consider primary breast carcinoma but not metastases. Methods. Immunohistochemical characteristics in 11 triple negative breast carcinomas were studied in both primary lesions and lymph node metastases. All cases were reevaluated to estrogen and progesterone receptors and HER2-Neu. An FISH probe for HER2/neu was also performed. Immunohistochemical studies were performed with cytokeratin 5/6, 17, Cam 5.2, p63, EGFR, and Ki-67 in breast carcinoma and lymph node metastases. Results. The age of the patients ranged between 42 and 73 years (mean 53), and the mean followup was 68.25 months. A total of $54.55 \%$ of the patients were disease-free, and $45.45 \%$ died of carcinoma. Axillary lymph nodes maintained triple negative phenotype (11/11). Metastatic tumors showed CAM 5.2 $(81.83 \%)$ and EGFR $(72.73 \%)$ expression. Basal marker expression was variable in primary carcinoma and lymph node metastases (63.64\%). Conclusions. Triple negative breast carcinomas maintained this immunoprofile at lymph node metastases. Triple negative carcinomas showed variable expression of basal cell markers.
\end{abstract}

\section{Introduction}

Breast cancer is a heterogeneous disease in terms of presentation, morphology, molecular profile, and response to therapy. Breast carcinoma gene expression profiling can be classified into five major biologically distinct intrinsic subtypes: luminal A, luminal B, HER2/neu overexpression, basallike (BLBC), and normal-like [1-3]. Of these five intrinsic subtypes, basal-like breast cancers have attracted particular attention, because they express neither estrogen receptors (ER), progesterone receptors (PR), nor HER2 and, therefore, would not be expected to benefit from anti-estrogen hormonal therapies or trastuzumab [4].

Although gene expression profiling is considered to be the gold standard method for identifying BLBC, cost and complexity issues have rendered it impractical as a routine hospital diagnostic tool. However, some immunohistochemistry studies have been proposed to identify BLBC, including the "triple-negative phenotype" (TNP) consisting of ERPR-HER2-negative [5] and the "five-marker panel" [6, 7] consisting of ER-PR-HER2-negative and epidermal growth factor receptor (EGFR) or cytokeratin 5/6 (CK5/6) positive. Most studies consider primary breast carcinoma but not metastases. In this study, we analyzed eleven cases of the phenotype of the triple-negative breast carcinoma with lymph node metastases to determine whether the triple negative phenotype is maintained at the site of metastasis. We also studied the histopathologic and immunohistochemistry characteristics of lymph node metastases, and we compared these findings with the homologous breast carcinoma.

\section{Materials and Methods}

Between 2001 and 2006, samples of triple negative breast carcinoma with lymph node metastases were located in the files of the Pathologic Anatomy Department at the Sant 
TABLE 1: Clinicopathologic and immunohistochemical characteristics of paired primary and lymph node metastatic triple negative breast carcinoma.

\begin{tabular}{|c|c|c|c|c|c|c|c|c|c|c|c|c|c|c|}
\hline Patient & $\begin{array}{c}\text { Age } \\
\text { (Years) }\end{array}$ & $\begin{array}{c}\text { Tumor size } \\
(\mathrm{mm})\end{array}$ & PT & $\mathrm{pN}$ & $\begin{array}{l}\text { Followup } \\
\text { (months) }\end{array}$ & Vital status & $\begin{array}{c}\text { ER } \\
(\mathrm{P} / \mathrm{L}) \\
\end{array}$ & $\begin{array}{c}\mathrm{PR} \\
(\mathrm{P} / \mathrm{L}) \\
\end{array}$ & $\begin{array}{c}\text { HER2 } \\
(\mathrm{P} / \mathrm{L}) \\
\end{array}$ & $\begin{array}{c}\text { CK5/6 } \\
(\mathrm{P} / \mathrm{L}) \\
\end{array}$ & $\begin{array}{c}\text { p63 } \\
(\mathrm{P} / \mathrm{L})\end{array}$ & $\begin{array}{c}\text { CAM5.2 } \\
(\mathrm{P} / \mathrm{L})\end{array}$ & $\begin{array}{l}\text { EGFR } \\
(\mathrm{P} / \mathrm{L}) \\
\end{array}$ & $\begin{array}{l}\text { CK17 } \\
(\mathrm{P} / \mathrm{L}) \\
\end{array}$ \\
\hline 1 & 55 & 24 & 2 & $\begin{array}{c}1 \\
(1 / 21)\end{array}$ & 82 & $\begin{array}{c}\text { Alive } \\
\text { DF }\end{array}$ & $-1-$ & $-1-$ & $-1-$ & $+1-$ & $+1-$ & $+/+$ & $2 / 2$ & $-/+$ \\
\hline 2 & 42 & 26 & 2 & $\begin{array}{c}3 \\
(5 / 25)\end{array}$ & 37 & $\begin{array}{c}\text { Alive } \\
\text { DF }\end{array}$ & $-1-$ & $-1-$ & $-1-$ & $+/-$ & $-1-$ & $+/+$ & $0 / 2$ & $+/+$ \\
\hline 3 & 65 & 21 & 2 & $\begin{array}{c}2 \\
(4 / 20)\end{array}$ & 42 & $\begin{array}{c}\text { Alive } \\
\text { DF }\end{array}$ & $-1-$ & $-1-$ & $-1-$ & $+/+$ & $+/+$ & $+/+$ & $1 / 0$ & $-1-$ \\
\hline 4 & 55 & 60 & 4 & $\begin{array}{c}3 \\
(18 / 19)\end{array}$ & 42 & Died & $-1-$ & $-1-$ & $-1-$ & $+/+$ & $+1-$ & $+/+$ & $1 / 2$ & $+/+$ \\
\hline 5 & 62 & 65 & 4 & $\begin{array}{c}2 \\
(8 / 11)\end{array}$ & 47 & Died & $-1-$ & $-1-$ & $-1-$ & $+/+$ & $+/+$ & $-1+$ & $1 / 3$ & $+/+$ \\
\hline 6 & 72 & 70 & 3 & $\begin{array}{c}3 \\
(20 / 22)\end{array}$ & 77 & $\begin{array}{l}\text { Alive } \\
\text { DF }\end{array}$ & $-1-$ & $-1-$ & $-1-$ & $-1-$ & $-1-$ & $+/+$ & $2 / 2$ & $-1-$ \\
\hline 7 & 63 & 18 & 1 & $\begin{array}{c}1 \\
(2 / 24)\end{array}$ & 117 & $\begin{array}{l}\text { Alive } \\
\text { DF }\end{array}$ & $-1-$ & $-1-$ & $-1-$ & $-1-$ & $-1-$ & $-1-$ & $0 / 0$ & $-1-$ \\
\hline 8 & 56 & 30 & 2 & $\begin{array}{c}1 \\
(1 / 18)\end{array}$ & 65 & $\begin{array}{c}\text { Alive } \\
\text { DF }\end{array}$ & $-1-$ & $-1-$ & $-1-$ & $+/+$ & $-1+$ & $+/+$ & $2 / 3$ & $+/+$ \\
\hline 9 & 69 & 60 & 3 & $\begin{array}{c}2 \\
(2 / 11)\end{array}$ & 39 & Died & $-1-$ & $-1-$ & $-1-$ & $+/+$ & $+/+$ & $+/+$ & $3 / 3$ & $+/+$ \\
\hline 10 & 58 & 60 & 3 & $\begin{array}{c}3 \\
(23 / 26)\end{array}$ & 84 & Died & $-1-$ & $-1-$ & $-1-$ & $-1+$ & $-1+$ & $+/+$ & $2 / 2$ & $-/+$ \\
\hline 11 & 73 & 20 & 2 & $\begin{array}{c}2 \\
(4 / 20) \\
\end{array}$ & 58 & Died & $-1-$ & $-1-$ & $-1-$ & $-1-$ & $-1-$ & $+/+$ & $2 / 0$ & $-1-$ \\
\hline
\end{tabular}

DF: disease-free; P: primary breast carcinoma; L: lymph node metastases.

Joan University Hospital, Reus, Tarragona (Spain). Clinical data were collected from clinical charts, referring physicians and/or pathologic reports. In total, 11 samples were identified. They were all reevaluated to estrogen receptor, progesterone receptor, and HER2-neu, in both primary and lymph node lesions. An FISH probe for HER2/neu was also performed in primary carcinoma without genetic amplification in all cases. A triple negative tumor was considered to study if no expression of ER, PR (Allred score 0\%), and Her2-neu was obtained.

Immunohistochemistry (IHC) analysis was performed on formalin-fixed, paraffin-embedded breast cancer, and lymph node tissues. Sequential $4-\mu \mathrm{m}$ were stained using Envision Flex (Dako Corporation, Denmark) and the autostaining system (Dako, Autostainer Plus, Denmark) with antibodies directed against the estrogen receptor (Dako, Clone 1D5, 1/35, pH6 retrieval), the progesterone receptor (Dako, Clone PgR36, 1/70, pH6 retrieval), Her2/neu (Dako, Polyclonal, 1/250, pH6 retrieval), CAM 5.2 (Novacastra, Clone 5D3, 1/100, pH6 retrieval), cytokeratin 5/6 (Dako, Clone D5/16B4, prediluted, pH9 retrieval), cytokeratin 17 (Dako, Clone E3, prediluted, pH9 retrieval), p63 (Dako, Clone 4A4, prediluted, $\mathrm{pH} 6$ retrieval), and the epidermal growth factor receptor (EGFR) (Dako, Clone E30, prediluted, $\mathrm{pH} 6$ retrieval). The tumor was considered positive for cytokeratins and p63 when cytoplasmic (and/or membrane) and nuclear staining was observed in at least $5 \%$ of tumor cells, respectively. EGFR IHC used only cell membrane localization to interpret. The intensity of the membrane staining was defined by a semiquantitative score $(0$ to $3+)$. For analysis purposes, $3+$ staining, defined as uniform and intense membrane staining in more than $30 \%$ of invasive breast cancer cells, was considered overexpression. No staining or weak incomplete membrane staining was considered a negative result.

The statistical analysis was performed using relative and absolute frequencies and the Spearman coefficient to determine the correlation between the immunohistochemical markers. A $P$ value below 0.05 was considered to indicate statistical significance.

\section{Results}

3.1. Clinical Findings. The patient group included 11 females with an average age of 53.4 years (range $42-73$ years). The mean followup was 62.72 months (range $37-117$ months), and the pathologic tumor stage was pT2 (20\%), pT3 (40\%) and pT4 (40\%). Five patients died of carcinoma (45.4\%). There was no significant difference for each group. Table 1 summarizes the most important clinical results.

\subsection{Histopathologic Findings}

3.2.1. Breast Carcinoma. Conventional HE histopathologic staining showed solid architecture and a high histologic grade (G3), a high mitotic index ( $>20$ mitosis/10 HPF), 


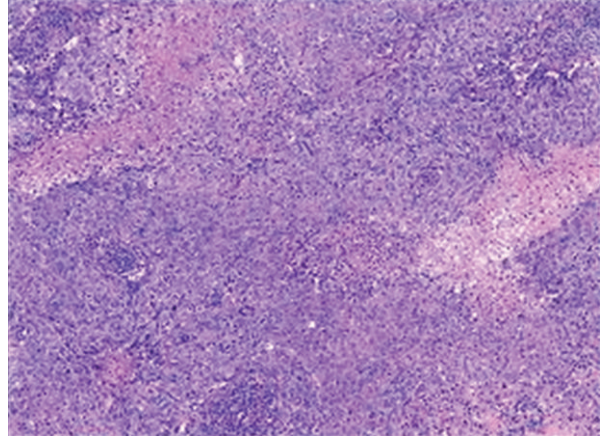

(a)

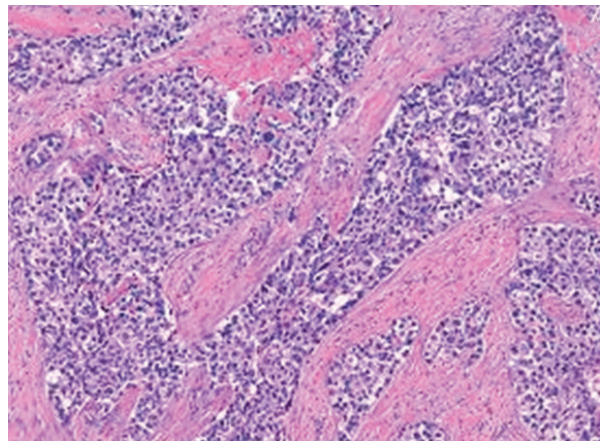

(c)

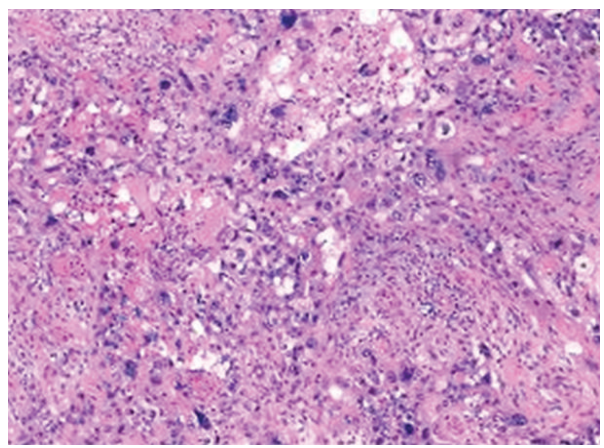

(e)

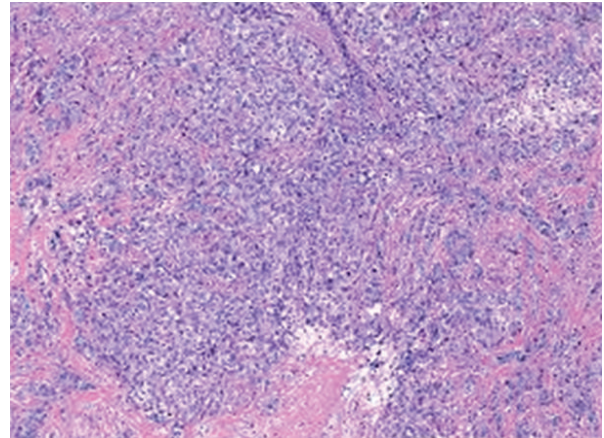

(b)

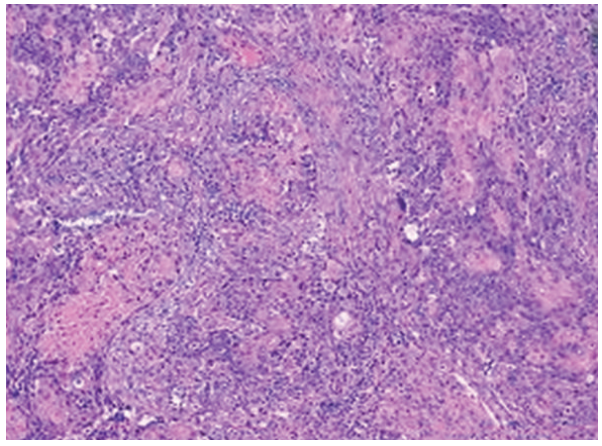

(d)

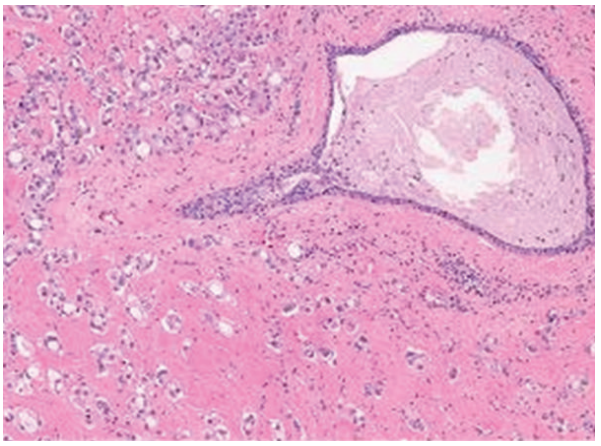

(f)

FIgURE 1: Triple negative breast carcinoma. (a, b) Solid architecture and high histologic grade, geographic necrosis, and no tubule formation is observed (HE, 100x). (c, d, e) High nuclear to cytoplasmic ratio and metaplastic components (squamous differentiation) are seen (HE, 200x). (f) Tubule formation with cytoplasmic borders clearly defined (Grade 2) (HE, 200x).

geographic necrosis and no tubule formation, a high nuclear to cytoplasmic ratio, scant cytoplasm, round to oval nuclei, a nuclear chromatin pattern that ranged from coarse to vesicular, and prominent nucleoli in 7 out of the 11 samples (63.6\%) (Figure 1). Two tumors showed metaplastic components, including squamous differentiation and poorly differentiated areas similar to sarcomatoid transformation (Figure 1). In two out of the eleven tumors the morphological pattern was tubule formation (Grade 2) with clearly defined cytoplasmic borders, round nuclei and prominent nucleoli. No geographic necrosis was observed (Figure 1).
3.2.2. Lymph Node Metastases. In eight samples, the metastatic carcinomas were characterized by a massive and diffuse lymph node affectation with a solid pattern, no tubule formation and no geographic necrosis. Tumor cells showed a high nuclear ratio, scant cytoplasm, oval nuclei, prominent nucleoli, and occasional multinucleated cells (Figure 2). In two samples, the metastatic cells showed different patterns. In one, tubular and squamous areas were clearly identified (Figure 2(e)), while in the other, the pattern was tubular metastatic (Figure 2(f)). In both cases, there was a correlation with the primary tumor that showed squamous areas (Figure 1(d)) and tubular formation (Figure 1(f)). 


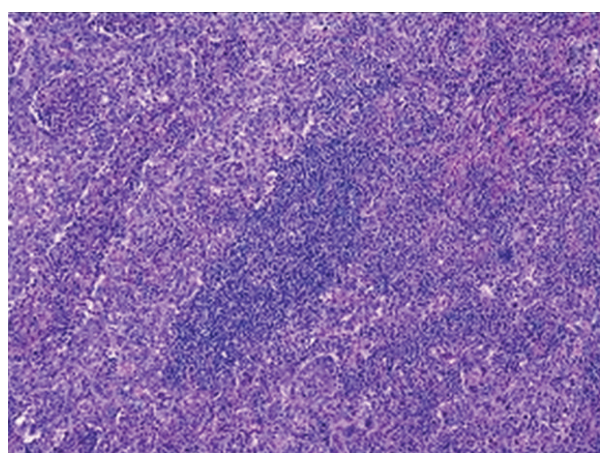

(a)

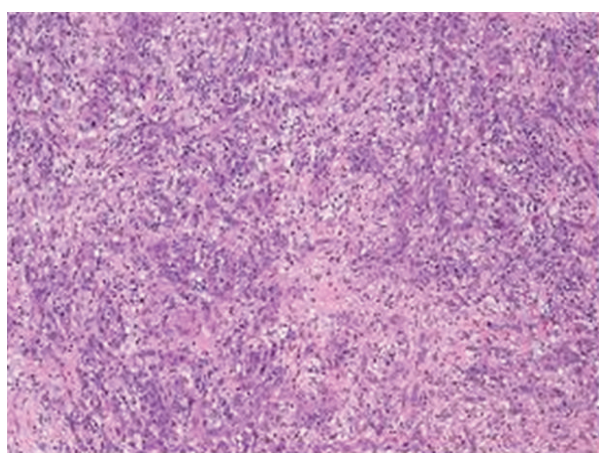

(c)

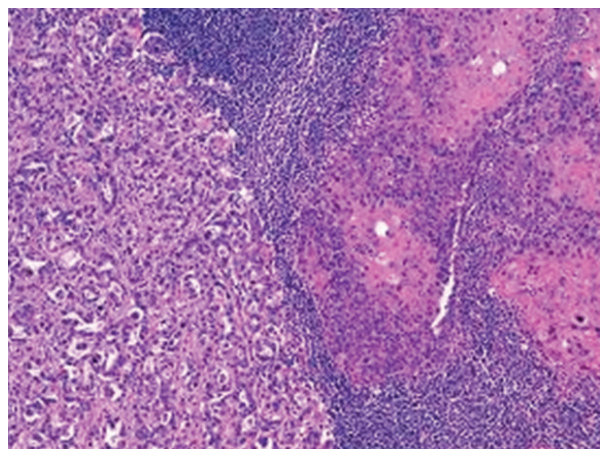

(e)

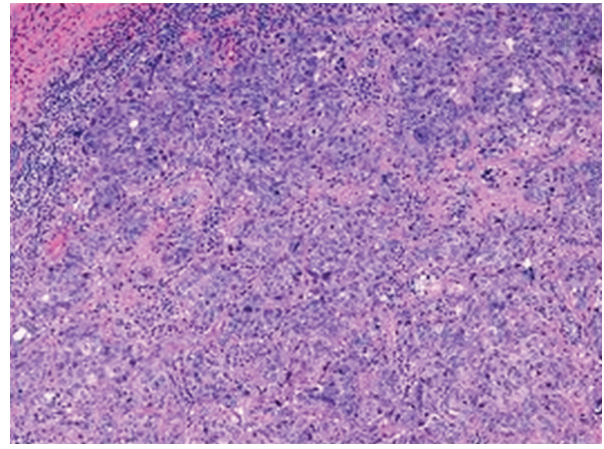

(b)

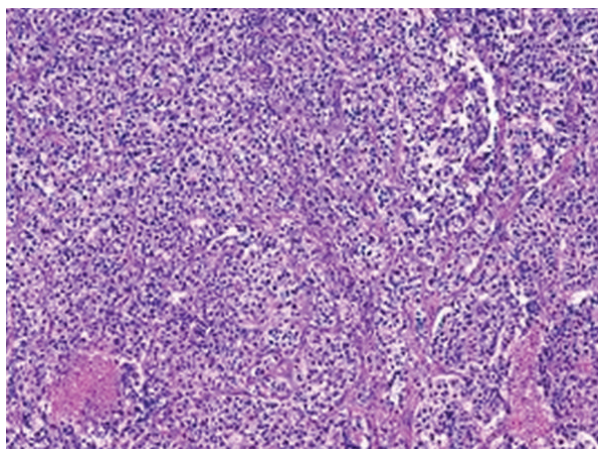

(d)

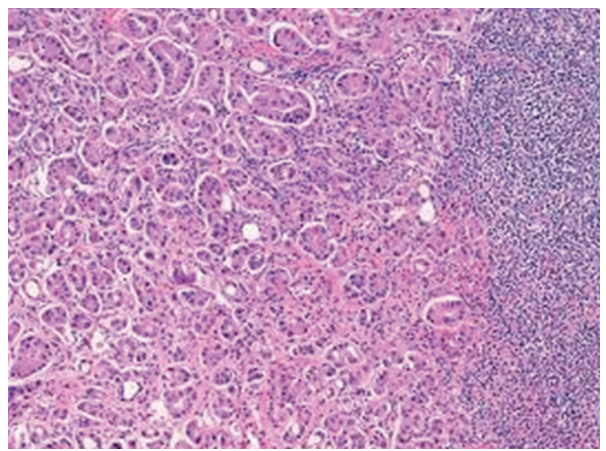

(f)

Figure 2: Histopathologic lymph node metastases in triple negative breast carcinomas. (a, b, c, d) Massive and diffuse lymph node affectation with solid pattern, no tubule formation, and no geographic necrosis was observed (HE, 100x, and 200x). (e) Tubular and squamous areas are clearly identified (HE, 200x). (f) Tubular metastatic pattern (HE, 200x).

\subsection{Immunohistochemical Findings}

3.3.1. Breast Carcinoma. Immunohistochemical stains for ER, PR, and HER2/neu were negative (11/11). Most tumors (9/11) demonstrated luminal cytokeratin expression to $8 / 18$ (CAM 5.2) with variable cytoplasmic and membrane staining, followed by EGFR (8/11). Two samples (4 and 9) showed the expression of five antibodies, and four were positive to four antibodies. In three samples there was coexpression to cytokeratin 5/6, 17, and p63; two showed cytokeratin 5/6 and 17 expression, and two others were positive for cytokeratin 5/6 and p63. Only two samples were negative to CAM 5.2, one of which, sample 5 , had cytokeratin 5/6, cytokeratin 17 , and p63 positivity. Sample 7 showed no reactivity to cytokeratins, p63 or EGFR.
3.3.2. Lymph Node Metastases. All the samples were negative for ER, PR, and HER2/neu (11/11). Most tumors (10/11) demonstrated expression of luminal cytokeratin 8/18 (CAM 5.2) with variable staining pattern. EGFR was positive in the same number of case $(8 / 11)$. Four samples were positive to five markers (cases 5, 8, 9, and 10), and three samples to three markers. In the rest of the lymph node metastases, antibody expression varied. As in breast carcinoma, sample 7 showed no reactivity to any of the antibodies.

\subsubsection{Immunohistochemical Correlation between Breast Carci- noma and Lymph Node Metastases. In both breast carcinoma and lymph node metastases, there was no expression to hor- mone receptors and HER2/neu (11/11). CAM 5.2 expression}


was seen in $90.9 \%$, and only one sample showed no expression in breast carcinoma and lymph node metastases. EGFR increased from $1+$ or $2+$ positive staining to $3+$ in $36.4 \%$ of the samples ( $P$ value 0.6573$)$. Four lymph node metastases showed increased expression of antibodies with positivity of five antibodies (Figure 3).

\section{Discussion}

It is difficult to determine the incidence of triple negative breast carcinoma. Basal-like carcinomas have been regarded as triple negative tumors in a variety of studies $[2,6,8,9]$, but some carcinomas in this group have been shown to express hormone receptors $[4,10]$. In a study based on the subtyping of breast cancer by immunohistochemistry, a total of 10,159 cases tumors were analyzed: $78 \%$ were luminal, $6 \%$ nonluminal HER2-positive, and 16\% triple negative breast carcinomas [11]. In our study, we found that triple negative breast carcinoma had an incidence of $11.85 \%$. This low frequency probably reflects a strict inclusion criteria for triple negative carcinomas, such as absolutely no expression of hormone receptors or HER2/neu.

Histopathologically, most of our BLBC showed the typical findings already described in these tumors (e.g., high grade carcinomas, with pushing, noninfiltrating borders of invasion, large zones of necrosis, lack of tubule formation, marked cellular pleomorphism, and prominent nucleoli) $[12,13]$. At lymph node level, there was a correlation between the appearance of primary carcinoma and metastases, but classical geographic necrosis, described in BLBC, was not seen at the lymph node. There were no typical histopathologic findings in three cases, but there was a good histological correlation between metastases and primary lesion, showing tubular formation and/or heterologous differentiation.

In our immunohistochemical analysis, ER, PR, and HER-2 showed $100 \%$ concordance between primary and metastatic tumors, which is consistent with previous reports in ER, PR, and HER-2 status in lymph node, liver, and lung metastases [14-17]. When the five marker method was used for analysis [6,7], $81.8 \%$ of samples were classified as BLBC (9/11) and $18.2 \%(2 / 11)$ as triple negative nonbasallike carcinomas (TNNBLBC) at the primary lesion. At lymph node metastases, there was a similar proportion of BLBC and TNNBLBC. Three samples are worthy of particular comment. Sample 7 showed a TNNBLBC in paired primary and metastatic TN breast carcinomas, with no expression of CAM5.2 (luminal cytokeratin marker). In this particular case, we confirmed the epithelial nature by the cytokeratin AE1/AE3 expression. Samples 10 and 11 showed phenotypic changes: TNNBLBC to BLBC (gain of CK5/6 and EGFR) in sample 10 and BLBC to TNNBLBC (loss of CK5/6 and EGFR) in sample 11. These findings showed that TN breast cancers encompass a heterogeneous group of tumors, and the expression of basal markers probably identifies distinct subgroups of TN tumors. An increase in EGFR was also observed in $36.4 \%$ of cases. These changes probably represent different biological behaviour or a different response to treatment. Confirmatory larger-scale studies, on metastatic BLBC and TNNBLBC, are warranted.
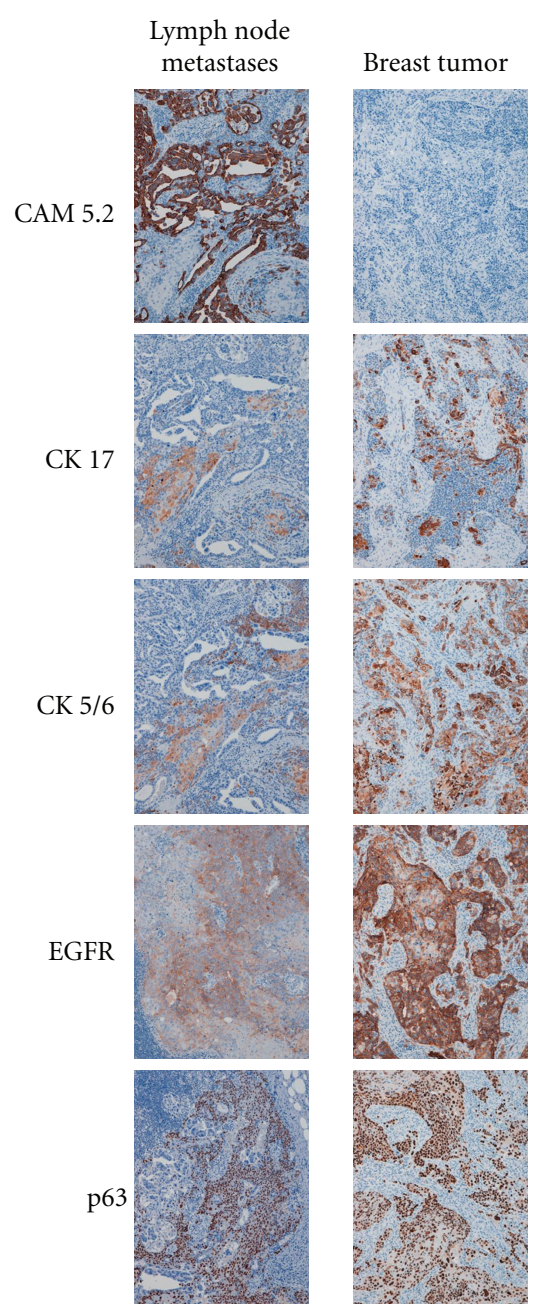

FIgure 3: Case 5 showing immunohistochemical comparative results in both lymph node metastases and breast primary tumor.

In conclusion, we analyzed a group of patients with basal-like breast carcinoma and lymph node metastases, who showed different expressions of immunohistochemical markers. Our results confirm that BLBCs are a heterogeneous group and probably have different prognoses and predictive factors.

\section{References}

[1] C. M. Perou, T. Sørile, M. B. Eisen et al., "Molecular portraits of human breast tumours," Nature, vol. 406, no. 6797, pp. 747$752,2000$.

[2] T. Sørlie, C. M. Perou, R. Tibshirani et al., "Gene expression patterns of breast carcinomas distinguish tumor subclasses with clinical implications," Proceedings of the National Academy of Sciences of the United States of America, vol. 98, no. 19, pp. 10869-10874, 2001.

[3] T. Sørlie, R. Tibshirani, J. Parker et al., "Repeated observation of breast tumor subtypes in independent gene expression data sets," Proceedings of the National Academy of Sciences of the United States of America, vol. 100, no. 14, pp. 8418-8423, 2003. 
[4] D. J. Slamon, B. Leyland-Jones, S. Shak et al., "Use of chemotherapy plus a monoclonal antibody against her2 for metastatic breast cancer that overexpresses HER2," New England Journal of Medicine, vol. 344, no. 11, pp. 783-792, 2001.

[5] B. G. Haffty, Q. Yang, M. Reiss et al., "Locoregional relapse and distant metastasis in conservatively managed triple negative early-stage breast cancer," Journal of Clinical Oncology, vol. 24, no. 36, pp. 5652-5657, 2006.

[6] T. O. Nielsen, F. D. Hsu, K. Jensen et al., "Immunohistochemical and clinical characterization of the basal-like subtype of invasive breast carcinoma," Clinical Cancer Research, vol. 10, no. 16, pp. 5367-5374, 2004.

[7] L. A. Carey, C. M. Perou, C. A. Livasy et al., "Race, breast cancer subtypes, and survival in the Carolina Breast Cancer Study," Journal of the American Medical Association, vol. 295, no. 21, pp. 2492-2502, 2006.

[8] S. Calza, P. Hall, G. Auer et al., "Intrinsic molecular signature of breast cancer in a population-based cohort of 412 patients," Breast Cancer Research, vol. 8, no. 4, article no. R34, 2006.

[9] C. Fan, D. S. Oh, L. Wessels et al., "Concordance among geneexpression-based predictors for breast cancer," New England Journal of Medicine, vol. 355, no. 6, pp. 560-569, 2006.

[10] F. Moinfar, "Is 'basal-like' carcinoma of the breast a distinct clinicopathological entity? A critical review with cautionary notes," Pathobiology, vol. 75, no. 2, pp. 119-131, 2008.

[11] F. M. Blows, K. E. Driver, M. K. Schmidt et al., "Subtyping of breast cancer by immunohistochemistry to investigate a relationship between subtype and short and long term survival: a collaborative analysis of data for 10,159 cases from 12 studies," PLoS Medicine, vol. 7, no. 5, pp. 1-12, 2010.

[12] E. Rakha and J. S. Reis-Filho, "Basal-like breast carcinoma: from expression profiling to routine practice," Archives of Pathology and Laboratory Medicine, vol. 133, no. 6, pp. 860868, 2009.

[13] E. A. Rakha, J. S. Reis-Filho, and I. O. Ellis, "Basal-like breast cancer: a critical review," Journal of Clinical Oncology, vol. 26, no. 15 , pp. 2568-2581, 2008.

[14] M. Tanner, P. Järvinen, and J. Isola, "Amplification of HER$2 /$ neu and Topoisomerase II $\alpha$ in primary and metastatic breast cancer," Cancer Research, vol. 61, no. 14, pp. 5345-5348, 2001.

[15] A. Vincent-Salomon, M. Jouve, P. Genin et al., "HER2 status in patients with breast carcinoma is not modified selectively by preoperative chemotherapy and is stable during the metastatic process," Cancer, vol. 94, no. 8, pp. 2169-2173, 2002.

[16] R. J. Broom, P. A. Tang, C. Simmons et al., "Changes in estrogen receptor, progesterone receptor and Her-2/neu status with time: discordance rates between primary and metastatic breast cancer," Anticancer Research, vol. 29, no. 5, pp. 15571562, 2009.

[17] J. S. Koo, W. Jung, and J. Jeong, "Metastatic breast cancer shows different immunohistochemical phenotype according to metastatic site," Tumori, vol. 96, no. 3, pp. 424-432, 2010. 


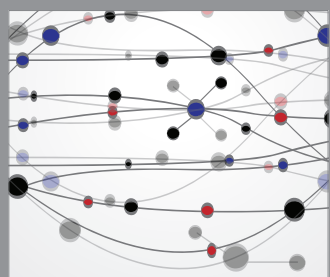

The Scientific World Journal
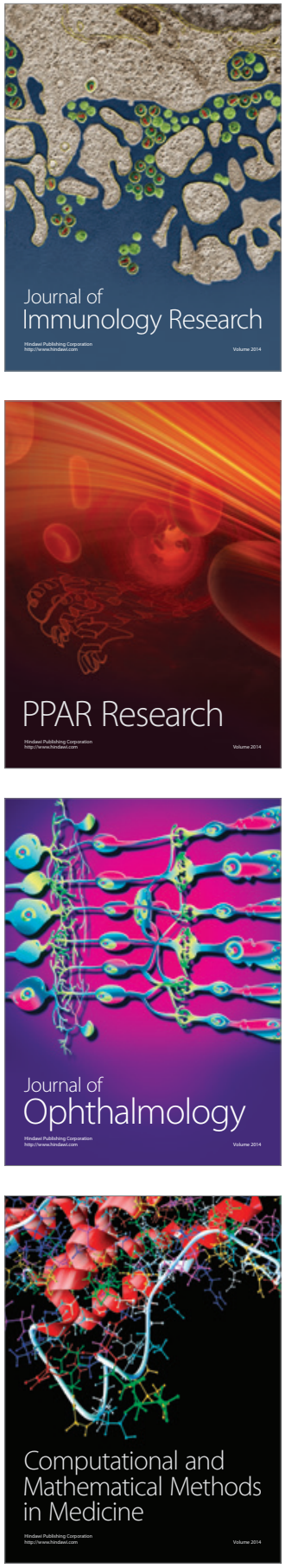

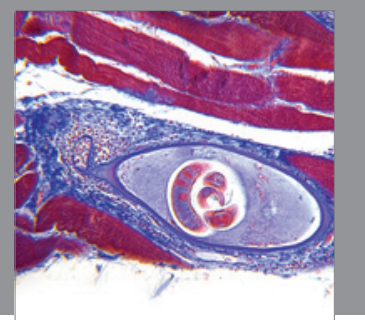

Gastroenterology

Research and Practice
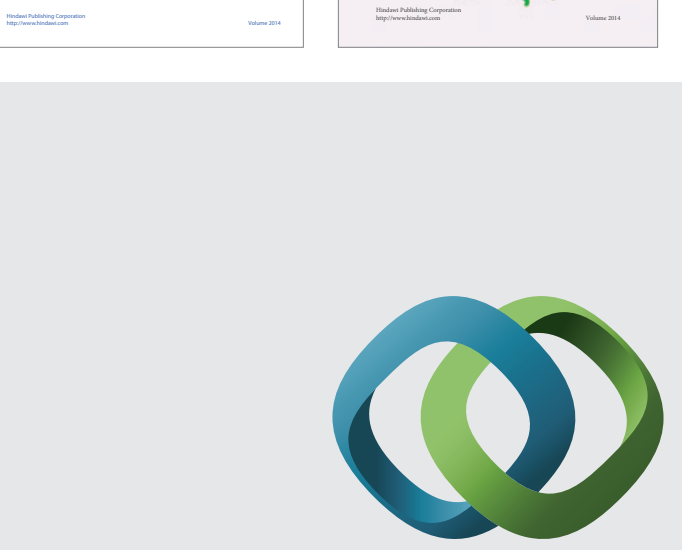

\section{Hindawi}

Submit your manuscripts at

http://www.hindawi.com
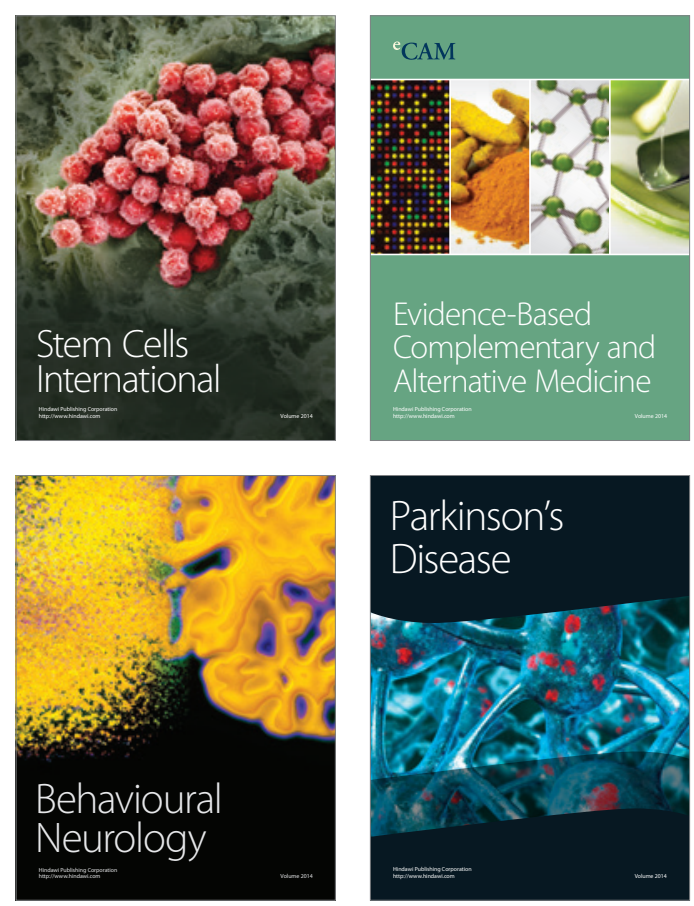

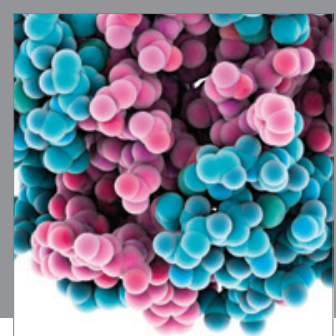

Journal of
Diabetes Research

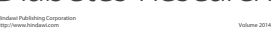

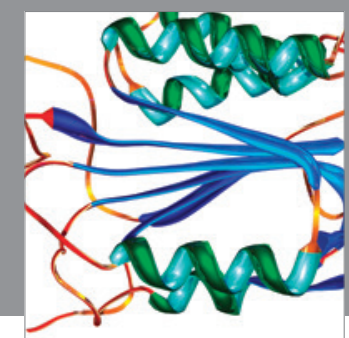

Disease Markers
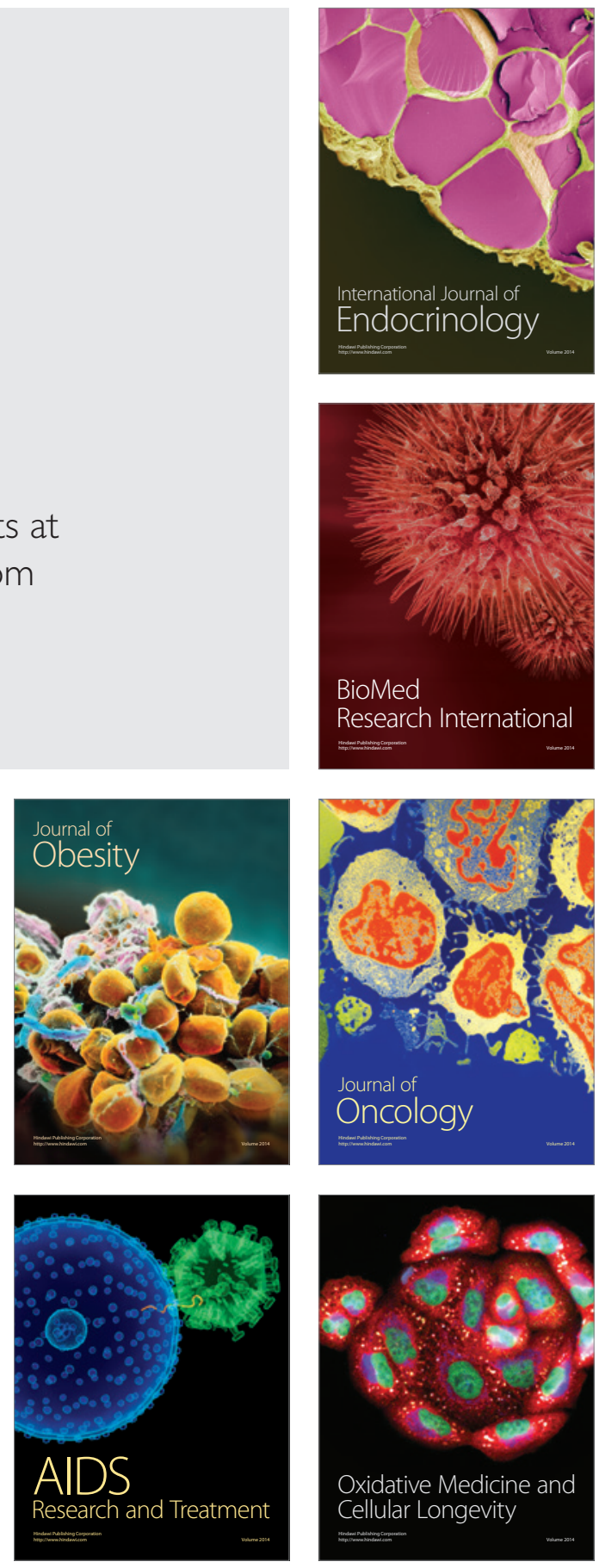